\title{
A FRAGMENTAÇÃO TEMPORAL NA OBRA MARIA DE CADA PORTO, DE MOACIR LOPES
}

\section{Lanaiza do Nascimento Silva Araújo*}

(D) https://orcid.org/0000-0001-5742-8196

Como citar este artigo: ARAÚJO, L. do N. S. A fragmentação temporal na obra Maria de cada porto, de Moacir Lopes. Todas as Letras - Revista de Lingua e Literatura, São Paulo, v. 23, n. 1, p. 1-13, jan./abr. 2021. DOI 10.5935/1980-6914/eLETLT 2113250

Submissão: abril de 2020. Aceite: novembro de 2020.

Resumo: O objetivo deste artigo é realizar um estudo em torno da fragmentação temporal presente no romance Maria de cada porto (1959), do escritor cearense Moacir Costa Lopes. A configuração temporal na obra se constitui por meio da tensão existente entre a cronologia das horas, marcada pelo presente da narração, e as rememorações que trazem evocações ao tempo passado, instaurando o tempo psicológico. O presente estudo pauta-se nas terminologias teóricas de Boris Tomachevski (1976) e Gérard Genette (1995) sobre a configuração do tempo na narrativa.

Palavras-chave: Fragmentação temporal. Cronologia. Rememorações. Maria de cada porto. Moacir Lopes. 


\section{INTRODUÇÃO}

M aria de cada porto, o primeiro romance de Moacir Costa Lopes, publicado em 1959, abre uma gama de escritos de Lopes no que se refere ao tema do mar. Michel Fody III (1978, p. 21) declara que tal obra "pode ser encarad[a] como o primeiro romance do mar no Brasil, abrindo uma área de experiência inteiramente nova nas letras brasileiras".

A referida narrativa conta a história de um grupo de marinheiros surpreendidos por um naufrágio e que passam quatro dias em alto-mar espalhados em balsas, enlouquecidos pela fome, sede e febre até o resgate quase improvável, quando muitos já haviam morrido. A narrativa é contada na perspectiva da personagem Delmiro, que vivencia o naufrágio e expõe o seu relato em primeira pessoa, em uma narrativa fragmentada em que passado e presente se confundem.

É possivel determinar que um dos recursos mais significativos que Moacir Costa Lopes utilizará nesta obra diz respeito à construção do tempo no romance. Conforme destacam Roland Bourneuf e Réal Ouellet (1976, p. 169), “o romance é, antes de tudo, considerado como uma arte temporal", pois a história narrada só se constitui dentro de uma configuração temporal, determinando se será narrada de forma linear ou não, se os episódios obedecerão a uma mesma velocidade narrativa ou se os fatos apresentados serão narrados em um intervalo longo ou curto de tempo. Toda história a ser contada depende de uma perspectiva temporal que a constitua.

Sendo assim, vemos que a história trágica do naufrágio que será narrada em Maria de cada porto assume, ao longo das páginas, um viés cada vez mais trágico e angustiante: os dias que passam e o salvamento que não chega, a loucura, a fome, a sede e a morte dos companheiros. Tudo isso marcado por um traço muito peculiar de solidariedade, camaradagem e amizade entre todos eles, além da luta, da resistência e da força daqueles homens do mar. Todavia, a narrativa não se concentra apenas na descrição do naufrágio, mas estará permeada de rememorações e voltas ao passado para retratar os eventos anteriores e contar a história de cada companheiro. Essa estruturação permite divisar como os elementos de ordem externa - no caso, a apresentação do naufrágio de 1945 e do contexto de guerra - serão trabalhados esteticamente na obra a fim de configurar os elementos internos de sua estrutura.

Tal configuração temporal é muito significativa no contexto da obra, pois os momentos vividos no presente através do naufrágio provocarão nesse narrador o desejo de relembrar o que acontecera até ali. Assim, serão descritas as viagens, o encontro com os companheiros, a história de cada um, os amores no porto, a vida no cais, os momentos vividos em outros navios, o contexto da guerra e suas repercussões. As longas horas sofridas que não passam serão vividas nas evocações dos tempos anteriores, capazes de trazer alegria para o coração do náufrago como forma de retardar um pouco a morte. Além disso, o fato de viver temendo a morte iminente produzirá uma espécie de reflexão e balanço em torno da vida.

Com isso, teremos a demarcação do jogo pendular que define a estruturação de Maria, nesse caso, o jogo entre o passado e o presente, a vida e a morte, as lembranças e a tragédia. Tudo isso para contrastar e, sendo assim, reforçar e adensar ainda mais a situação de sofrimento vivida pelos náufragos. Esse jogo temporal está patente na mistura entre passado e presente da narração, provo- 
cando uma fragmentação temporal evidente. Somente no primeiro capítulo da obra aparece uma concentração mais notória no presente da narração. Todos os demais capítulos serão construídos nessa mistura temporal sem demarcações, provocando a fragmentação.

Isso pode ser destacado no modo como o presente da narração se constitui: são cinco dias entre o acontecimento do naufrágio e o salvamento, mas a distensão temporal se dá de tal forma que dentro desses cinco dias cabe a vida inteira das personagens. Tudo isso virá em forma de rememorações e teremos acesso a um número bem maior de acontecimentos, não somente do presente narrativo.

No que se refere à época histórica, vemos a narrativa concentrar-se no naufrágio do cruzador Bahia em 1945, que coincide com o fim da Segunda Guerra Mundial, mas veremos que alguns fatos narrados serão anteriores ao naufrágio, quando do início dessa guerra. É importante mencionar também que o narrador ainda fará evocações a um tempo anterior, um passado mais remoto, quando da sua infância e da sua entrada na escola de aprendizes marinheiros, mas não existe nenhuma menção efetiva com relação a datas que delimite precisamente esse período.

Vale examinar, assim, como a configuração temporal aparece estruturada na obra a partir das terminologias de fábula e trama: a fábula em si, ou seja, do enredo na sua sucessão cronológica de fatos e eventos, respeitando uma relação de causa e efeito; e a trama, isto é, o modo como os fatos são apresentados por uma instância narradora. Essas tipologias de fábula e trama ${ }^{1}$ são provenientes da teoria do Formalismo Russo, propostas por Boris Tomachevski (1976). Observamos um descompasso entre o tempo da fábula e o tempo da trama, evidenciado nas anacronias narrativas que aparecem em grande parte da obra. Conforme aponta Gérard Genette (1995, p. 34), tais anacronias narrativas se constituem quando existem "diferentes formas de discordância entre a ordem da história e da narrativa", reveladas a partir de dois procedimentos básicos: a analepse, "toda a ulterior evocação de um acontecimento anterior ao ponto da história em que se está" (p. 38), e a prolepse, "a manobra narrativa consistindo em contar ou evocar de antemão um acontecimento ulterior" (p. 38).

Observa-se, na narrativa em análise, que as analepses serão fartamente utilizadas ao longo do desenrolar dos fatos, exatamente quando a narração do naufrágio fica em suspensão e o narrador retoma fatos anteriores através das rememorações. As prolepses também são utilizadas em alguns momentos, mas de forma menos recorrente. Em contrapartida, destaca-se que ao lado das anacronias narrativas aparece também uma tentativa de exposição da sincronia narrativa, quando existe uma coincidência entre a ordem em que os eventos aparecem na fábula e a ordem em que os eventos aparecem na trama. Esses momentos de sincronia narrativa podem ser destacados na narração do presente diante da construção do tempo cronológico, em que existe uma tentativa de delimitar e relatar os fatos tal como aconteceram.

Sendo assim, no que diz respeito à ordem dos eventos relatados, ressalta-se que a narrativa se constrói na oscilação entre o tempo cronológico, apresentando a ordem natural dos fatos, e o tempo psicológico, em que veremos a ordem dos fatos ser ditada pelas reflexões conturbadas provocadas pelo naufrágio, impul-

Essas categorias são retomadas por Gérard Genette (1995) sob a acepção de história e narrativa, como também por Todorov (1971) utilizando a nomenclatura de história e discurso. 
sionando a volta ao passado, trazendo reminiscências e evocações a um tempo anterior dirigidas pela consciência de um narrador personagem.

Tomamos como tempo psicológico essa configuração que foge do tempo linear do relógio e se concentra no íntimo de quem narra. A disposição dos fatos virá a partir da psicologia do ser que conduz os fatos. No entanto, destacamos que o tempo psicológico em Maria de cada porto é diferente do tempo psicológico por excelência, que poderemos encontrar em uma obra de Clarice Lispector, como A paixão segundo G.H., por exemplo, que dá um grande espaço ao estado intimo, e a narração se perde nas reflexões subjetivas. Aqui, o tempo psicológico existe na medida em que observamos o narrador se concentrar em alguns momentos na conturbação provocada pelo naufrágio e ser impulsionado a fugir do tempo cronológico para empreender as recorrentes voltas ao passado. É o seu estado íntimo que determina a ordem da narração dos fatos, produzindo as várias oscilações entre o presente e o passado. Nossa análise se concentrará no estudo em torno destas duas configurações temporais: a cronologia das horas e as rememorações.

\section{A CRONOLOGIA DAS HORAS}

A obra se pauta, em alguns momentos, por uma certa cronologia. Inicialmente, observamos essa configuração no modo como os capítulos são nomeados, começando com o naufrágio e se estendendo na demarcação sucessiva dos dias que passam até fechar no porto seguro, o salvamento. Isso pode ser ainda mais evidenciado quando existe o relato, por parte do narrador, da marcação das horas que passam para os náufragos, menção ao dia da semana e do mês e o período em que estão naquela condição hostil e dificil:

O dia ia-se esvaindo vermelho por trás do mar, o segundo dia, uma quinta-feira de julho. Fiz meus cálculos em silêncio, somei, dividi e concluí ser aquele o último sol visto por mim.

Das quinze balsas morreram quatro pessoas nessa tarde, digo, treze balsas, porque duas debandaram na correnteza (LOPES, 2002, p. 117).

Pelo fragmento, observa-se a exatidão na marcação dos dias em que os marinheiros estão na condição de naufragados, o número de balsas que estão em alto-mar e, ainda, o número preciso das mortes naquele segundo dia. Cria-se a sensação de que o narrador parece ir destacando e anunciando pouco a pouco as proporções da tragédia: "Mais uma balsa largou-se de nós; restam agora dez ou doze, não sei; oitenta ou cem das duzentas e oitenta criaturas, se muito. Entre dois instantes alguém anuncia: fulano morreu, sicrano afundou, beltrano enlouqueceu" (LOPES, 2002, p. 133).

Essa exploração da cronologia dos dias e das horas destaca a proporção da tragédia e vai delineando o sofrimento e as dificuldades enfrentadas pelos marinheiros. No discurso do próprio narrador, ressalta-se a tentativa de recriar a cena do naufrágio, mencionando a quantidade exata das balsas e das pessoas que foram morrendo, ou, em algumas circunstâncias, a inexatidão na informação, pois a todo momento as balsas vão se perdendo umas das outras, ficando dificil precisar corretamente as informações.

O recurso da demarcação das horas e do número de mortos ou náufragos será muito pertinente para criar a atmosfera precisa da situação vivenciada, 
anunciando, pouco a pouco, em termos quantitativos, a passagem dos dias, o desgarrar das balsas que se perdem na correnteza e a chegada da morte já antevista por muitos:

Sei que restam dez ou doze balsas espalhadas, talvez cinquenta ou sessenta criaturas vivas, fora os peixes, que não vemos. As outras, as balsas vazias, debandaram para longe; vazias, não - com um cadáver, no fundo do estrado, a que ninguém pôde dar a sepultura dos nautas. Que injustiça, Meu Deus! (LOPES, 2002, p. 238).

Em cada descrição realizada pelo narrador, observa-se o adensamento da tragédia: o número de balsas vai diminuindo, o número de pessoas vivas também e a imagem que será construída é a de balsas vazias, carregando um cadáver em seu interior que não receberá nem ao menos a sepultura dos marinheiros. Tal situação é narrada em tom inconformado e triste, como a demarcar a injustiça sofrida naquele contexto desesperador, e se tornará ainda mais densa e difícil à medida que as horas passam e os dias avançam:

Estamos no fim do terceiro dia, a febre vai subindo em meu corpo, meus olhos estão se apagando, tudo escurece. Por mais de uma vez vi sombras de navios no horizonte; pergunto a Arigó e ele julga que estou à beira da loucura. A febre e os pensamentos me enlouqueceram realmente. Na madrugada de hoje delirei, o corpo todo tremeu, tive falta de respiração, a língua parece um trapo seco espremendo um pedaço de cortiça; nem tenho mais saliva (LOPES, 2002, p. 189).

A narração, cada vez mais, evidencia a tragédia e o sofrimento quando destaca o fim do terceiro dia. Os sintomas de febre e loucura já tomam o narrador, que sequer consegue mais narrar o número de balsas nem de marinheiros que permanecem vivos. O seu estado de saúde impede a informação precisa como vínhamos conhecendo há pouco. Em termos de técnica narrativa, tal construção torna-se reveladora e rica como forma de ressaltar como a situação sofrida ganha similaridade em relação à estruturação dos fatos narrados.

Assim, fica patente que a exploração da cronologia e a narração do presente tornam marcante a situação trágica e desesperadora do naufrágio, destacando a passagem ritmada e lenta das horas para quem o vivencia, bem como evidenciando o tardar na possibilidade de salvamento. O clima da narração torna-se angustiante, os dias que passam e a morte que se aproxima, a deterioração de tudo ao redor, balizando um jogo antitético: as horas se delimitam e passam para a frente e o número de vivos vai diminuindo cada vez mais, deixando clara a descrença no salvamento e já dando como certa a morte que se aproxima.

Em contrapartida, o que se destaca é que, em alguns momentos da narrativa, o tempo cronológico se esfacela e será dado espaço ao narrar dos momentos sofridos na condição de náufragos. Sendo assim, teremos acesso aos pensamentos do narrador, que vive a angústia e o sofrimento nas balsas. Nesses momentos confessionais temos um narrador perdido em suas próprias reflexões; assim, o tempo cronológico fica em suspensão e aparece a perspectiva psicológica do ser que narra:

Ouço o riso de Dolores, vejo Nina fazendo o rol da roupa e dizendo que quer me dar um amor bem grande, e vem alguma coragem, mas essa própria coragem morre da sede, e fica o mar, caminho tolo que Deus abriu no meio da terra só para largar nele uns peixinhos que, afinal de contas, nem raciocinam porque 
estão aqui. Brincadeira de Deus, quando era criança travessa e, só por ser Deus, quis ter um aquário maior que todos os aquários dos homens, emendados (LOPES, 2002, p. 113-114).

As reflexões do narrador revelam a concentração nos seus sentimentos mais subjetivos, evocando as lembranças de Dolores e de Nina que o encorajam, mas, logo em seguida, a coragem é sufocada pelo sofrimento diante da sede, que o leva a questionar a criação do mar por Deus. Nesse momento vemos o ser que se perde nas divagações e pensamentos diante da dificil condição enfrentada.

Em outros momentos da obra, encontramos o reforço na descrição das dificuldades nas balsas ao mostrar o sofrimento, o medo da morte, o desejo por alcançar o porto, mas uma desesperança em relação a voltar a pisar algum dia nele. Teremos acesso à conturbação interior da personagem, ao modo como ela enxerga o naufrágio, ao sofrimento pela morte dos companheiros, ao medo da morte iminente, aos assomos de loucura provocados por tantos dias tortuosos de fome e sede. Nos últimos instantes das personagens como náufragos, a loucura e o delírio passam a ser uma marca constante desse tempo que nega a cronologia das horas e se volta para a interiorização.

Tal configuração ganha ainda mais destaque quando o próprio relógio, símbolo do tempo cronológico através do contar das horas, passa a ser descrito por toda uma visão psicológica dramática de quem enxerga o fim como próximo:

Olhava para o relógio nas mãos de Tiozão e parecia ouvir-lhe as batidas dos segundos, batidas gordas, enormes. Seriam as batidas de meu sangue, nas têmporas, do sangue dos outros, nas têmporas dos outros? Ninguém me diria estar aquele relógio parado. Não estava! Era o coração do dono que morrera; está trabalhando à toa, não sabe que seu dono morreu. Ou é meu coração? Ele também marca os segundos da vida que terei. Esta noite, a pior de todas, vai se arrastar muito comprida, muito feia (LOPES, 2002, p. 246).

O relógio do companheiro Eduardo, que acabara de morrer, passa a ser espaço de reflexão para enfatizar a morte do dono, bem como para fazer referência à batida dos segundos que ainda restavam na vida daqueles náufragos. O relógio só ganha sentido quando funciona para marcar os segundos de vida, mas no contexto do naufrágio ele é sintomático para destacar os segundos que apontam para a morte, ou os míseros segundos de vida que ainda restam. Nesse sentido, vemos o tempo funcionar sob a perspectiva psicológica do ser que o enxerga e produz suas reflexões pessimistas, fazendo alusão clara à chegada da morte, antevista na noite "comprida" e "feia" que a própria personagem anuncia. Não existe esperança, mas a constatação do término definitivo de tudo.

Essa cena reflexiva diante do relógio do companheiro morto pode ser vista como o auge do drama vivido pelas personagens, destacando o esfacelamento do tempo cronológico como sendo o último instante de lucidez provado por eles. $\mathrm{O}$ relógio corporificaria a ligação com o mundo dos vivos, mas ele também perde o seu significado ao ser percebido sem funcionamento:

Observo Tiozão brincando com o relógio aberto, analisando seu mecanismo enferrujado, num meio sorriso. Deu corda. Inútil. Tentou dar movimento à máquina com o dedo. Inútil. Retirou o vidro do mostrador e dispôs-se a rodar para trás o ponteiro grande. Por que para trás? Foi contando as horas em voz alta, retrospectivas; compreendi sua brincadeira e lhe dei razão: Tiozão teve uma infância também (LOPES, 2002, p. 253). 
Na cena descrita, o relógio parado corporifica a imagem da morte que se aproxima, dos minutos que não existem mais, do tempo que foi vivido e não voltará. Por isso é que a imagem de Tiozão tentando consertar o objeto e brincando com os ponteiros de forma a tentar voltar no tempo revela o grande desejo de retomar a vida já passada, sair da condição sofrida, enxergar uma possibilidade de vida que não existe mais no contexto assolador do naufrágio. O relógio sem funcionamento potencializa o drama vivido pelas personagens.

$\mathrm{Na}$ manhã seguinte a essa longa noite, quando todas as esperanças pareciam estar extintas e o fim já havia sido anunciado pelo narrador, os marinheiros parecem avistar a sombra de um navio; pensam ser uma ilusão, mas enxergam depois que de fato o socorro chegara. O balanço da situação só será descrito depois do salvamento, quando a personagem já conseguiu recuperar-se de sua fraqueza e volta a narrar os fatos do presente, numa retomada do tempo cronológico:

Trinta e três pessoas apenas foram recolhidas pelo Balfe, tendo morrido a maior parte de nossa guarnição. Algumas balsas, as que se desgarraram do grupo, ainda estavam ao léu: o Balfe não pudera localizá-las; os tripulantes dessas balsas estariam morrendo e sem esperança, pois entrávamos no sexto dia. Dos oficiais do Bahia, um apenas fora recolhido - não o conhecia (LOPES, 2002, p. 260).

Vemos a exatidão dos números e uma espécie de resumo da atual situação depois do salvamento pelo navio inglês SS Balfe. A narração da obra mostra-se fiel ao relato histórico do naufrágio. Sabe-se que foram 33 resgatados, dos quais apenas um oficial sobreviveu. No quinto dia, o salvamento havia chegado, mas a grande parte da tripulação estava morta ${ }^{2}$.

Diante dessas considerações sobre a configuração temporal, percebe-se a oscilação entre a cronologia das horas e as reflexões subjetivas do personagem que se perde em sua conturbação interior, esfacelando a passagem das horas e dos dias. Isso se torna ainda mais concreto quando enxergamos que, ao lado de toda a cronologia, existe também uma justaposição de fatos que apontam para eventos anteriores ao presente narrado, produzindo as rememorações através dos constantes recuos temporais.

\section{AS REMEMORAÇÕES}

As rememorações e evocações a tempos anteriores, tão constantes ao longo da obra, funcionam como forma de trazer um pouco de vida e manter a chama acesa para que os náufragos não morram mais depressa. Essa volta ao passado por meio dos recuos temporais, as analepses, trarão para a narração os momentos vividos antes do naufrágio. Tudo será contado pouco a pouco: a história de vida do narrador e das personagens, a entrada para a Marinha, os dias em alto-mar, a alegria e a vivência nos portos, o contexto da guerra em Recife e Natal, o encontro com as mulheres e com os anônimos da rua.

Desde o primeiro capítulo já se constata essa configuração. A primeira rememoração empreendida pelo narrador diz respeito a sua Nina, filha da lavadeira.

2 De acordo com os Subsídios para a história marítima do Brasil, "verifica-se que apenas 9,6\% da guarnição do Bahia escapou com vida ao maior drama até agora vivido em águas brasileiras. Trezentos e trinta e três companheiros tombaram heroicamente no cumprimento do dever" (SERVIÇO DE DOCUMENTAÇÃO DA MARINHA, 1948, p. 7). 
Ao relembrar de Nina, lembrará do seu Recife, anunciará a cidade em plena situação de conflito, as mudanças provocadas, o progresso que a guerra trouxe e as problemáticas ali vivenciadas. Sua narração destaca ainda como conheceu Nina e alguns companheiros, aborda as más condições do navio, os dias em alto-mar e a situação do marinheiro na guerra. Enfim, a terceira seção do primeiro capítulo será uma justaposição de tempos e fatos para esquecer a condição de náufrago:

Recife de antes e depois da guerra é estabelecido, tem seu nome feito pelos cantos da terra, a eternidade gravada em suas pontes, nos presídios de centos de anos, nos símbolos de cada época; mas o Recife que lembro agora não é eterno. O que preciso de lembrar, para esquecer esta balsa em que estou mergulhado, nádegas rijas a tanto de molho, já velho deste estrado duro, é daquela mutação vertiginosa, a correnteza do progresso vindo de arribada com a guerra, a universalização da gente. No meio de tudo, Nina, a filha da lavadeira, que não tem pressa, porque o amor está em toda parte para ela (LOPES, 2002, p. 29).

Observamos de forma patente o desejo de relembrar o passado para esquecer da situação vivenciada, destacando o Recife e seu progresso, a efervescência da vida, a movimentação vertiginosa que se opõe à condição de náufrago dentro do estrado duro, parado no tempo, imóvel. Em seguida, a rememoração voltará para Nina, a sua Maria do porto, descrita como possuidora de tempo, que não tem pressa de viver e que poderia trazer um pouco de vida para esse ser tão solitário.

Fato pertinente a notar neste ponto é o modo como a narração será construída de forma episódica, como se o narrador estivesse a flagrar em pequenos flashes um conjunto de rememorações. Nesse sentido, teremos um painel sendo formado para demarcar toda a configuração social destacada por Delmiro em suas evocações. A construção se dá numa mistura de tempos e numa justaposição de episódios, narrados sem demarcação, de forma rápida e abrupta, separados apenas por asteriscos:

A coisa era assim:

- Estamos em guerra - gritavam.

- Ora, aproveitemo-la.

- Não ouviu direito

- Guerra, homem! O mundo está em guerra! [...]

- Já sabes dançar o swing, Carmem?

- Por que não? É só pular.

- E não tens uma semana aqui, hein?

- A gente aprende depressa.

- Que tal os gringos?

- Pagam bem. Cem, duzentos cruzeiros. E adormecem logo, não são como os brasileiros [...]

Você sabe por que tanta gente adoeceu nos navios?

- Não. Sei é que havia gente dependurada no pau da surriola ontem.

- Foi a carne que comemos. Não se lembra, você reclamou?

- Lembro. 
- Era de cachorro, aquela carne.

- Não diz! [...]

- Delmiro...

- Diga, Olivia... [...]

Olivia pertencia a um grupo de garotas da Casa Amarela, bairro pobre; trazia consigo uma intenção e a expressava:

- Não quero ser pobre. A pobreza é grosseria! [...]

Mas por que tanta gente apressada? Pudera, isso é o instantâneo de um povo em evidência!

Nina era diferente.

- Nina, tenho necessidade de pecar com você. Arrie essa trouxa de roupa e me ame. Pelo amor de Deus, Nina! (LOPES, 2002, p. 29-39).

Como se percebe nos fragmentos dispostos acima, existe nesta seção da obra uma justaposição de fatos. A narração concentra-se na demarcação do contexto social preciso, destacando o período da Segunda Guerra e suas repercussões. Veremos, ainda, a caracterização desse cenário de guerra, as suas repercussões na cidade de Recife, o progresso que chega com a guerra, o dinheiro dos americanos que impulsionam o lucro, a vida noturna e musical com destaque para o swing, ritmo que os americanos difundiram no período.

Mais adiante, a narração concentra-se na descrição das más condições de vida no navio, destacando os problemas em relação à comida, que, de acordo com os tripulantes, era carne de cachorro. De forma repentina, o trecho seguinte irá apresentar a personagem Olivia, prostituta que sonha com riquezas e que namora com o narrador personagem por dois anos. Por fim, os fatos seguintes destacam uma movimentação que podemos pensar ser a das ruas e das cidades, e a descrição novamente da personagem feminina, Nina, a filha da lavadeira, a menina que despertava amor em Delmiro.

Observa-se assim que há uma mistura de tempos e de fatos narrados de forma abrupta, sem preocupação com o estabelecimento de linearidade ou causalidade, trazendo uma fragmentação evidente para o discurso, já que revela a impossibilidade de sustentação de um discurso ordenado, pois os fatos narrados são produto da subjetividade do narrador, que ao rememorar desfaz a ordenação lógica do relato.

O fato é que existe uma representação do contexto social vivenciado por aquelas personagens sem a demarcação precisa do tempo em que os fatos ocorrem. Vemos a situacionalidade histórica em torno do contexto da guerra e sua repercussão na cidade do Recife, mas os fatos serão apresentados de maneira episódica, sem uma correlação entre o que estava sendo narrado anteriormente e o que virá a ser retratado a seguir.

Essa configuração define muito bem como existe na obra uma discrepância entre o tempo da trama e o tempo da fábula. Os fatos não são apresentados como de fato aconteceram, buscando respeitar a causalidade, mas sim a partir de uma ordenação caótica, revelando um verdadeiro descompasso entre tempos.

A narração do naufrágio fica em suspensão enquanto os fatos narrados voltarão para o tempo passado, que será descrito também de forma não linear, numa mistura de episódios com o intuito de ir demarcando o que o romance 
virá a mostrar. O leitor terá uma introdução diante do contexto da obra, mas somente algumas informações, pois o narrador nos fará ir conhecendo tudo aos poucos, mantendo o fio da narração nesse constante voltear temporal.

Esse traço é muito recorrente ao longo de toda a narrativa de Maria de cada porto, pois percebe-se que os fatos serão ditados pela corrente psíquica da personagem, que, abalada pela sua condição de náufrago, deixará vir até sua memória tudo o que viveu outrora. Sendo assim, essas lembranças não poderão vir de forma concatenada nem linear, mas serão apresentadas tal como acontecem, numa mistura e justaposição de fatos e tempos.

Todavia, vale ressaltar que esses momentos de rememoração chegam de forma presentificada, narrados como sendo fatos do presente e não do passado, pois são relatados com todos os seus detalhes e minúcias. Assim, na maioria desses momentos teremos a construção de cenas buscando retratar com fidelidade os eventos anteriores ao naufrágio. Nesse sentido, pela força das descrições, veremos o alongamento dos eventos relatados e uma demora na volta ao presente narrativo ${ }^{3}$. Essa configuração cria em muitos momentos da obra uma sensação de monotonia, quando existe a vasta descrição da rotina no navio e dos vários personagens. O recurso é pertinente para caracterizar as longas horas que não passam para os náufragos e criar uma expectativa diante do desfecho da obra.

Tal construção temporal, tão significativa em Maria de cada porto, oscila, assim, entre os dias de naufrágio, destacando o tempo cronológico, e os dias de marinhagem anteriores ao acidente, determinando o passado vivido de forma fragmentada e misturando tempos e fatos. Essa configuração temporal é que estrutura a obra. Todavia, percebemos que nem sempre essa oscilação entre tempos se dá de forma muito separada na narrativa. O que torna a construção temporal ainda mais expressiva é que esses tempos narrados mudam de forma repentina e rápida, conforme observamos no fragmento a seguir:

Toda situação é contornável, mas olhamos em torno e vemos tubarões passeando, mais longe o mar emenda com o céu e não vemos saída; e dentro da balsa, meus companheiros se acabando, enlouquecendo, morrendo.

Eu começava vida nova no dia em que recebemos o Baependi. Houve solenidade com discursos. Falou o Almirante Ari Parreiras, falou o almirante americano Ingram [...]

Hoje, as pequenas lembranças, os pequeninos atos têm grande importância para mim. Lembro-me até daquele cão fedorento, cheio de moscas que entrou na praça-d'armas à hora da refeição e prostrou-se ante os oficiais (LOPES, 2002, p. 114-115).

Por meio do fragmento, percebe-se essa modificação temporal de forma repentina. No primeiro momento, os fatos relatados se situam no presente da história, descrevendo a situação no contexto do naufrágio, quando repentinamente a narração passa a relatar os fatos de um tempo passado relativo ao contexto de guerra. Por fim, mais à frente, a narração retoma os eventos do presente narrativo, destacando o narrador protagonista valorizando as suas lembranças de outrora.

3 No quarto capítulo do romance, a narração do presente aparece apenas nas três primeiras páginas. Todas as outras 18 páginas do capítulo são uma retomada dos eventos que antecedem o naufrágio. 
Chama a atenção o modo como em apenas poucas linhas temos essa movimentação temporal que mescla os tempos, essa oscilação evidente na apresentação dos fatos, produzindo um verdadeiro descompasso entre o tempo da fábula e o tempo da trama. Essa peculiar configuração temporal, além de oscilar de forma abrupta, sem demarcações, ainda aparece, em alguns momentos, como uma espécie de confluência entre os tempos, que se misturam e se confundem, ficando dificil demarcar seus limites precisos.

Isso pode ser destacado em um dos momentos de delírio e de sonho, impulsionado pelo desejo da personagem de esquecer a sua condição e se libertar do sofrimento vivenciado. Vislumbra-se, assim, um momento extremo de mistura de tempos, o tempo interior e o tempo presente, que se confundem e se sobrepõem:

Calaram-se e capacitei-me de que era mesmo Nina que piscava os olhos lá de cima para mim. Esqueci as nádegas, o corpo inteiro de molho, abandonei-o e fui subindo até encostar os lábios na estrela Nina. Cheguei morto pela fome e sol e mar e sede, vindo de um naufrágio. Nina não reparou que eu estava morto $e$ conversamos muitos dias seguidos; pedi-lhe para ir até meu quarto buscar a roupa dessa viagem; mentira, eu não tinha roupa, pois tudo afundara. Senti um frio enorme e ela acendeu o fogo, tomamos café com biscoitos. Peguei seu corpo e senti que realmente revivia e o possuí. Então ela disse que precisava brilhar. No caminho assustou-se, apontando para baixo:

- Estou vendo umas coisas boiando, Delmiro.

- Não olhe para baixo, Nina. Aquilo foi um naufrágio e os homens estão morrendo porque ninguém os socorre.

- Mas você está ali também! Está nu, pálido, parece que tem febre. - E cobriu o rosto com as mãos e chorou.

Olhei então, vi as balsas afastando-se pela correnteza, e numa delas estava realmente eu, em meio a outros homens calados e muitos tristes, e peguei frio. Escorreguei das mãos de Nina e fui cair dentro da balsa, quando ouvi os gritos de Mundico (LOPES, 2002, p. 59).

Nesse episódio, vemos a concentração inicial no tempo psicológico, em que o narrador parece criar na imaginação um encontro no céu com sua estrela Nina e lá de cima observar o que acontece nas balsas abaixo. Estão marcadas nesse discurso sonhador e delirante uma tentativa de fuga e uma possibilidade de não encarar o naufrágio, quando o narrador vislumbra um encontro com Nina e destaca uma expectativa de futuro. Todavia, abruptamente, a cena é desfeita quando Nina olha para baixo e observa os náufragos dispostos em balsas. De repente, o próprio narrador passa a enxergar sua condição de náufrago. Essa percepção é um chamamento à realidade. Existe a descrição da queda do personagem do céu para dentro da balsa. Tal queda sugere também uma queda temporal, do tempo subjetivo para o tempo presente. A narração deixa de ser ditada pelo tempo psicológico e delirante da mente e cai dentro da realidade do naufrágio.

Essa passagem destaca na exata proporção a fluidez e a mistura temporal da obra: os tempos se coadunam e se unem. A mente ditará a ordem dos acontecimentos e, como o tempo é interior, o discurso torna-se fragmentado, embaralhado, modificando-se de forma contínua e rápida. A estruturação temporal prefigura a temática narrada, o discurso delirante do narrador que vai sobrepondo e misturando os tempos. Pode-se dizer que o tempo "vivencia" a mesma queda de Delmiro: do céu festivo com sua Nina para a realidade torturante da narrativa 
do presente. Esse jogo temporal construirá de forma exata o contexto dificil e assolador do naufrágio. Tal procedimento temporal é muito utilizado nas obras de Moacir Costa Lopes, transformando-se em uma das características mais definidoras de sua técnica narrativa.

\section{CONSIDERAÇões FINAIS}

Conclui-se, assim, que a representação do naufrágio e da guerra como cerne da narrativa parte de todo um substrato histórico real, mas vemos como tais fatos se transformam em seiva narrativa pelo modo como a construção da obra se coloca. O naufrágio é narrado por meio desse jogo temporal, que demarca na cronologia dos capítulos e no destaque dos dias que passam, das balsas que somem na correnteza e dos companheiros que morrem, o tom desesperador e angustiante da situação sofrida. Ao lado da cronologia das horas, destaca-se a concentração no tempo subjetivo do narrador, que expõe de forma ainda mais contundente nos delírios e sentimentos de sua mente conturbada todos os efeitos dos dias de fome, sede e febre, mas nos permite voltar a tempos anteriores para conhecer todo o contexto daqueles náufragos e trazer um pouco de vida para um cenário de morte e dor.

Nesses termos, é curioso observar que, se demarcar a cronologia dos fatos, horas e números recriam e caracterizam o ambiente hostil e trágico do naufrágio. Suspender esse presente para empreender uma volta ao passado será um recurso largamente utilizado ao longo da obra como forma de recriar a demora no salvamento e os longos dias que não passam, bem como de retardar o desfecho da tragédia e assim aguçar a curiosidade do leitor, mas, ainda assim, trazendo um pouco de vida e felicidade a náufragos que nada mais vislumbram além da morte ou adensando a tragédia na medida em que as lembranças felizes entram em contraste com o naufrágio, que parece extinguir qualquer possibilidade de vida futura. Essa configuração temporal internaliza os dados externos, trazendo significado para a estruturação que ganha homologia com os fatos apresentados e traz grande expressividade para essa obra de Moacir Lopes.

\section{Temporal distortion In MOACIR LOPES' NOVEL MARIA DE CADA PORTO}

Abstract: This article aims to conduct a study around the temporal distortion in Maria de cada porto (1959), by the writer Moacir Costa Lopes. The novel's temporal configuration is constituted by the tension existing between the chronology of hours, marked by the present of the narration, and the remembrances that bring evocations to the past time, establishing psychological time. This study is based on the theoretical terminologies of Boris Tomachevski (1976) and Gérard Genette (1995) on the configuration of time in the novel.

Keywords: Temporal distortion. Chronology. Remembrances. Maria de cada porto. Moacir Lopes.

\section{REFERÊNCIAS}

BOURNEUF, R.; OUELLET, R. O universo do romance. Tradução José Carlos Seabra Pereira. Coimbra: Livraria Almedina, 1976. 
FODY III, M. Criação e técnica no romance de Moacir C. Lopes. Tradução Ilza Viegas e José Augusto Carvalho. Rio de Janeiro: Cátedra, 1978.

GENETTE, G. Discurso da narrativa. 3. ed. Alpiarça: Vega, 1995.

LISPECTOR, C. A paixão segundo G.H. Rio de Janeiro: Rocco, 1998.

LOPES, M. C. Maria de cada porto. 9. ed. Rio de Janeiro: Editora Quartet, 2002.

SERVIÇO DE DOCUMENTAÇÃO DA MARINHA. Subsídios para a história marítima do Brasil. Rio de Janeiro: Imprensa Naval, 1948. v. IV.

TODOROV, T. As categorias da narrativa literária. In: BARTHES, R. et al. Análise estrutural da narrativa. Tradução Maria Zélia Barbosa. 3. ed. Petrópolis: Vozes, 1971.

TOMACHEVSKI, B. Temática. In: EIKHENBAUM, B. et al. Teoria da literatura: formalistas russos. 2. ed. Porto Alegre: Globo, 1976. p. 169-204. 